\title{
COMPARTILHAMENTO DE UMA MEMÓRIA MIDIÁTICA EM GRUPOS DO FACEBOOK PELOS MIGRANTES BRASILEIROS NA SUÉCIA
}

\author{
LAURA RORATTO FOLETTO \\ UNIVERSIDADE FEDERAL DE SANTA MARIA \\ SANTA MARIA, RIO GRANDE DO SUL, BRASIL \\ LAURA.RORATTO@GMAIL.COM
}

HTTP://DX.DOI.ORG/10.5902/2316882X23050 


\section{COMPARTILHAMENTO DE UMA MEMÓRIA MIDIÁTICA EM GRUPOS DO FACEBOOK PELOS MIGRANTES BRASILEIROS NA SUÉCIA}

Resumo: Este artigo procura-se entender os usos sociais que migrantes brasileiros na Suécia realizam acerca de formação de uma audiência compartiIhada, com o compartilhamento de uma memória midiática nos grupos do Facebook. Realizou-se uma combinação de diversos procedimentos metodológicos, como formulários e entrevistas. As discussões desses migrantes acerca da mídia ajudam a construir, reforçar e tensionar suas identidades, ao passo que contribui, também, para se sentirem pertencentes a um grupo, o de migrantes brasileiros na Suécia.

Palavras-Chave: mídia; Facebook; brasileiros na Suécia; migrantes

\section{COMPARTIR DE UNA MEMORIA DE MEDIOS EN GRUPOS DE LO FA- CEBOOK POR LOS MIGRANTES BRASILEÑOS EN SUECIA}

Resumen: En este artículo se busca entender los usos sociales que los migrantes brasileños en Suecia hacen sobre la formación de una audiencia compartida, con compartir una memoria de medios de comunicación en los grupos de Facebook. Hemos llevado a cabo una combinación de diversos procedimientos metodológicos, con formularios y entrevistas. Las discusiones de estos migrantes sobre los medios de comunicación ayudan a construir, fortalecer y apriete sus identidades, al tiempo que contribuye también a sentirse parte de un grupo, de los migrantes brasileños en Suecia.

Palabras-Clave: medios de comunicación; Facebook; brasileños en Suecia; migrantes

\section{SHARING OF A MEDIA MEMORY IN THE GROUPS OF FACEBOOK BY BRAZILIAN MIGRANTS IN SWEDEN}

Abstract: This article seeks to understand the social uses that migrants Brazilian migrants in Sweden held about forming a shared audience with sharing a media memory in Facebook groups. It was conducted a combination of various methodological procedures, such as forms and interviews. Discussions of these migrants about the media help to build, strengthen and tighten their identities, while contributing also to feel part of a group, the Brazilian migrants in Sweden.

Keywords: media; Facebook; Brazilian in Sweden; migrants 


\section{Introdução}

Com a globalização e com novas as tecnologias de informação e comunicação (TICS), o acesso à informação se tornou mais facilitado; entretanto, a internet ainda não é acessível para todos, e as desigualdades se tornam visíveis. Segundo Furlan com base no relatório independente, intitulado "Redefinindo a Exclusão Digital" que foi lançado no Fórum Global de Banda Larga Móvel em 2013, os fatores que contribuem para a exclusão no acesso a internet é a renda e a acessibilidade, assim a exclusão digital corresponde a $63 \%$, seguidos de $56 \%$ que corresponde à falta de habilidades digitais para o uso das tecnologias digitais. Em 2013, segundo o portal R7, com base em um estudo realizado pela McKinsey\&Company, 4,4 bilhões de indivíduos estão completamente offline. Em 2014, segundo a Organização das Nações Unidas (ONU), o número de usuários da internet chegava a quase 3 bilhões no mundo, cerca de $40 \%$ da população mundial, o que significa que mais de 4 bilhões de pessoas ainda não têm acesso à internet. Em 2015, segundo relatório da União Internacional de Telecomunicações (UIT)da ONU 57\% da população mundial permanece desconectada, ou seja, não têm acesso à internet, sendo que $60 \%$ da população brasileira está conectada.Atualmente, uma das formas de uso da internet são os sites de redes sociaisonline como o Facebook.

Diante disso, as plataformas de redes sociais online estão atravessadas por uma tecnologia diferenciadora. Assim, compreende-se que a tecnicidade reformula as nossas práticas sociais e culturais por meio da tecnologia, que significa a complexidade no entendimento dos discursos - das relações de poder e do contexto histórico que constituem essas tecnologias. Além disso, implica a construção de práticas por meio de diferentes linguagens e escritas midiáticas. Ao estarmos frente ao computador, estamos entrelaçados em uma rede, muito mais complexa que um aparato técnico, em que há uma relação estabelecida, através de usos, práticas culturais e sociais, com a produção de conhecimento a partir dessa tecnologia diferenciadora. Portanto, a tecnicidade, terceira mediação proposta por Martín-Barbero (2009), corresponde mais a operadores perceptivos e destrezas discursivas do que a aparatos tecnológicos.

As TICs transformam nossos usos e apropriações. Isso significa uma transformação nas formas pela quais esses migrantes estão atuando nos grupos do Facebook, e os usos que fazem, impactando nos modos de estar

Rev.Cad.Comun. Santa Maria, v.20, n.3, art 11, p.205 de 212, set/dez.2016 
no mundo, bem como de se comunicar em rede.Diante disso, Martín-Barbero (2004) sugere duas formas por meio das quais essas tecnologias nos formulam:

\begin{abstract}
Tanto na racionalidade que materializam como no seu modo de operação, essas tecnologias põem em crise a "ficção de identidade" que na maioria de nossos países é a cultura nacional. [...]. Trata-se do início de uma nova configuração cultural, da articulação das identidades a partir de uma racionalização tecnológica que se constitui em motor de um projeto de nova sociedade (MARTíN-BARBERO, 2004, p. 181).
\end{abstract}

Há infinitas possibilidades de câmbios culturais, sociais, econômicos e políticos articulados à nossa configuração identitária. Deste modo, a nossa identidade é posta em jogo com a racionalização tecnológica.

A segunda formulação proposta pelo autor é de que

\begin{abstract}
...as novas tecnologias de comunicação [...] fazem visível o resto não-digerível, não-simulável, que desde a alteridade cultural resiste à homogeneização generalizada. Ao pretender varrer toda a diferença não-serializável, a racionalidade tecnológica movimenta resistências que não se esgotam na dissidência da contracultura ou na disfuncionalidade ao modelo, já que essas resistências configuram e prefiguram um modo de sociabilidade e de sociedade outro (MARTíN-BARBERO, 2004, p. 183).
\end{abstract}

As diferenças ganham sentido a partir TICs, ao ladodo contexto cultural e social em que os sujeitos estão inseridos. Em que essas tecnologias nos fazem questionar e analisar as diferentes formas de remodelar as identidades culturais (MARTÍN-BARBERO, 2004, p. 184).

Ao mesmo tempo em que as mídias tradicionais geram impacto nos usos sociais dos sujeitos, a internet também o faz, em que estão ligados a uma situação sociocultural que contribui para que os sujeitos reelaborem,ressignificem e ressemantizem os conteúdos massivos que recebem. Isso vai de acordo com sua experiência cultural, que suporta, orienta os meios de apropriações e de sentidos produzidos por esses sujeitos (JACKS; ESCOSTEGUY, 2005, p. 66), em que eles também setornam produtores com a internet.

Os meios de comunicação, bem como as plataformas na internet, como o Facebook, foram criados com um propósito. Porém, sabemos que os usos sociais que os sujeitos fazem dessas formas de comunicar variam. Os sujei-

Rev.Cad.Comun. Santa Maria, v.20, n.3, art 11, p.206 de 212, set/dez.2016 
tos não se "comportam exatamente como os criadores do sistema esperam ou desejam" (SHIRKY, 2011, p. 169), eles operam o sistema conforme a sua lógica de uso, subvertendo, portanto, o uso tradicional programado.

Entende-se que as tecnologias vão moldar nossas identidades ao passo que as identidades moldam as tecnologias e seus usos. Portanto, "a produção de identidades passa, necessariamente, pelas telas" (OROZCO, 2010, p. 24). Mas, na medida em que os usos das telas excedem a mera soma de possibilidades, há uma produção a partir da interação com as telas: a identidade. Uma identidade "amalgamadora", não tão essencialista; porém, uma identidade durável o suficiente para ser reconhecida, e flexível o suficiente para ser reproduzida repetidas vezes, modificada, trocada ou negociada (OROZCO, 2011, p. 392).

As identidades são fluidas e intercambiáveis ao longo de nossas histórias de vida, não são essências fixas. Os sujeitos estão construindo quem são e a onde pertencem a partir do contato com o outro e por meio das experiências e vivencias com outras culturas. As identidades no processo de migração tornam-se ainda mais mutáveis, em que as identidades são marcadas pela diferença (brasileiros x suecos). Segundo Woodward (199) "a diferença é aquilo que separa uma identidade da outra, estabelecendo distinções, frequentemente na forma de oposições" (p. 39). Nesse sentido, os sujeitos migrantes frente a esse contexto social e cultural diverso, ora reforçam sua identidade nacional ora reconstroem-se quem são por meio das múltiplas possibilidades identitárias.Portanto, "as identidades são diversas e cambiantes, tanto nos contextos sociais, nos quais elas são vividas, quanto nos sistemas simbólicos por meio dos quais damos sentido as nossas próprias posições" (WOODWARD, 1999, p. 33).

Com a globalização, as identidades e as culturas estão sempre em fluxo, constantemente em atualização. Por isso que "falar de identidades hoje implica também falar de migrações e mobilidades, de rede de fluxos, de instantaneidade e fluidez" (MARTÍN-BARBERO, 2006, p. 61). Os sujeitos podem assim pertencer, ao mesmo tempo, a vários grupos ou subgrupos, sem que a sua identidade entre em conflito, pois as nossas associações, enquanto sujeitos dotados de vontade, se dão de acordo com as necessidades individuais de pertencimento profissional e pessoal. 


\section{Objetivos}

Este artigo é proveniente dos resultados de pesquisa da dissertação de mestrado intitulada: "Usos sociais do Facebook por migrantes brasileiros na Suécia: identidades, diferenças e dinâmicas interculturais nas redes sociais online", cujo objetivo foi analisar os usos sociais que migrantes brasileiros na Suécia fazem de grupos do Facebook. Os grupos estudados na dissertação e que também contemplam o artigo são dois grupos fechados do Facebook de migrantes brasileiros na Suécia - "Brasileiros na Suécia"; "Brasileiros na Suécia/Svenskar i brasilien".

Neste artigo procurou-se entender os usos sociais que migrantes brasileiros na Suécia realizam acerca de formação de uma audiência compartilhada, com o compartilhamento de uma memória midiática no Facebook. Ou seja, o objetivo desse artigo compreende mostrar alguns dos resultados encontrados durante a pesquisa de mestrado. Dessa forma, partiu-se do entendimento dos usos sociais do Facebook atravessados pela mediação tecnológica para entendermos de que maneira as questões de identidade e diferença são tensionadas e negociadas nesses espaços comunicacionais.

\section{Considerações metodológicas}

Realizou-se uma combinação de diversos procedimentos metodológicos, como formulários online e entrevistas por Skype, além de analisar as postagens e comentários nos gruposacerca das questões estudadas.

O perfil dos 30 respondentes do formulário online é composto basicamente por mulheres ( 26 mulheres e quatro homens) com as idades que variam de 26 a45 anos, sua grande maioria da região Sudeste (18) e Sul (seis) do Brasil, em que 59\% da amostra possuem pós-graduação ou especialização. Já o perfil dos 10 entrevistados corresponde a sete mulheres e três homens com as idades que varia de 26 a 40 anos, nascidos na região Sudeste (oito) e Sul (dois) do Brasil. A amostra dos entrevistados corresponde a um perfil de alta escolarização e alta condição financeira devido à escolarização, as profissões e as condições de vida desses sujeitos antes de migrar.

\section{Principais resultados}

Os sujeitos migrantes usam o Facebook para compartilhar suas experiências acerca do que veem, escutam ou leem nos meios de comunicação de 
massa, fazendo dos grupos do Facebook um lugar de registro dessa memória midiática.

Os migrantes brasileiros na Suécia recordam e compartilham o que gostam e o que veem sobre o Brasil. Migrar não significa perder o vínculo com o país de nascimento, pelo contrário: percebemos uma memória midiática por parte desses migrantes que procuram, por meio de programas televisivos, notícias e celebridades brasileiras, reviver a memória sobre o país. Nesse sentido, a mídia constrói sentidos sociais e simbólicos, uma vez que proporciona contato, mesmo que virtualizado, com o Brasil e o compartilhamento nos grupos das impressões e dos sentimentos acerca do que veem e leem. Guardar na memória ou capturar por instantes as lembranças de um Brasil que ficou pra trás por meio da mídia ajuda os migrantes a se construírem como cidadãos que possuem múltiplos pertencimentos, pois ao mesmo tempo em que se identificam com a cultura brasileira, também se identificam com outras culturas, costumes e hábitos que podem ser locais ou globais.

É também por meio da mídia massiva no Facebook que programas da TV brasileira ganham importância e destaque na vida desses sujeitos migrantes, que no caso da migração ganha outro sentido e a importância é outra. A importância, muitas vezes, não é dada pelo conteúdo em si, mas pelo que determinados programas representam para o Brasil e para os brasileiros. Na vida desses sujeitos, a programação da mídia brasileira representa uma aproximação com o seu país de nascimento.De forma a ilustrar a importância dos programas televisivos brasileiros nessa construção identitária, temos a postagem do dia 18 de fevereiro de 2015 referente à procura por um canal de TV sueco que transmita os jogos da Libertadores da América'.

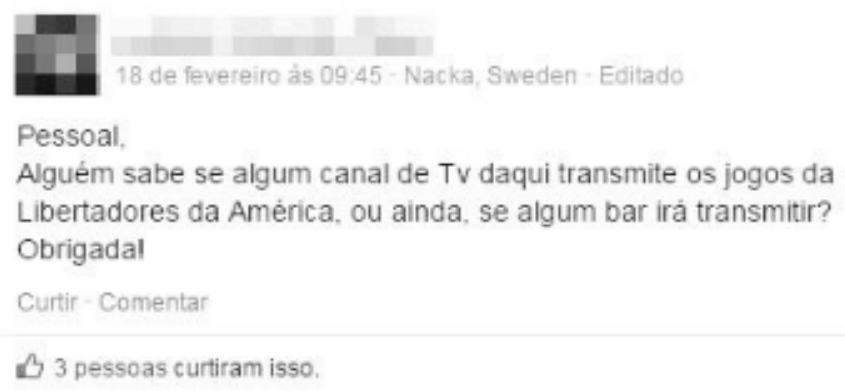

Imagem 60:Postagem no grupo "Brasileiros na Suécia/Svenskar i Brasilien” referente à busca por um canal de TV que transmita os jogos da Libertadores da América.

1 É um evento esportivo conhecimento como Copa da Libertadores da América que reuni times de toda a América do Sul para a disputa do título.

Rev.Cad.Comun. Santa Maria, v.20, n.3, art 11, p.209 de 212, set/dez.2016 
Essa postagem marca a importância do futebol, um esporte reconhecido mundialmente como uma atividade associada ao Brasil, assim como o carnaval, que se refere à cultura brasileira. $O$ carnaval e o futebol são atividades que se perpetuam no imaginário dos estrangeiros como associadas ao Brasil. Diante disso, marca e reforça a construção dessa identidade brasileira.

O fato de compartilharem no Facebook o que estão recebendo, seja na televisão ou em alguma outra mídia massiva, corresponde aos modos em que a audiência não se restringe mais ao ambiente off-line - a sala de televisão, aos vizinhos -, pois agora a audiência ampliou os modos de circulação do conteúdo: chegou ao online. Ao mesmo tempo em que estão vendo, ouvindo ou lendo algo em alguma mídia massiva, estão comentando nas redes.

Dessa forma, a mídia perpassa as discussões desses migrantes e ajuda a construir, reforçar e tensionar suas identidades - brasileira e migrante -, ao passo que contribui, também, para se sentirem pertencentes a um coletivo e construírem mecanismos de cooperação dentro do grupo. O consumo dessa mídia serve para a manutenção dos vínculos com o país de nascimento, de forma a não rompê-los.

\section{Conclusões}

A partir da análise apresentada, foi possível notar os diferentes usos sociais que esses sujeitos realizam nos grupos do Facebook para se construírem enquanto migrantes na Suécia. Compreende-se, assim, que as identidades são múltiplas e fluidas, que os migrantes estão construindo suas identidades a partir das suas experiências migratórias, do contato social e cultural com o país de nascimento e com o país receptor em que os usos da tecnologia vão impactar nessa experimentação da migração. Nessa multiplicidade de culturas, de espaços e de territórios, percebeu-se que os migrantes, ao longo da sua trajetória de migração, reconhecem a importância da mídia massiva, por meio da memória compartilhada no Facebook, em que gera aproximações, reconhecimentos e distanciamentos enquanto brasileiros na Suécia. Nesse sentido, foi possível observar que a negociação, o tensionameto e o reforço das identidades compõem os sujeitos, principalmente em situação de migração, e que eles estão o tempo todo construindo suas identidades.As identidades, por serem fluidas e intercambiáveis, estão sempre sendo tensionadas e negociadas nesses espaços, quecontribui para esses migrantes se construírem enquanto sujeitos identitários.

Rev.Cad.Comun. Santa Maria, v.20, n.3, art 11, p.210 de 212, set/dez.2016 
CADERNOS DE COMUNICAÇÃO

UNIVERSIDADE FEDERAL DE SANTA MARIA

\section{REFERÊNCIAS}

JACKS, Nilda; ESCOSTEGUY, Ana Carolina. Comunicação e Recepção. São Paulo: Hacker Editores, 2005.

Folha de São Paulo. Internet já tem quase 3 bilhões de usuários no mundo, diz ONU. Disponível em: http://www1.folha.uol.com.br/tec/2014/11/1553088-internet-ja-tem-quase-3-bilhoes-de-usuarios-no-mundo-diz-onu.shtml. Acessado em: 02/06/15.

FURLAN, Paula. Exclusão Digital e também exclusão social. Disponível em: http://b2bmagazine.consumidormoderno.uol.com.br/index.php/internet/item/3239-exclusao-digital-e-tambem-exclusao-social. Acessado em: 15/05/15.

MARTÍN-BARBERO, Jesús. Dos Meios às Mediações: mediações, comunicação, cultura e hegemonia. Rio de Janeiro: UFRJ, 2009.

Tecnicidades, Identidades, Alteridades: mudanças e opacidades da comunicação no novo século. IN: MORAES, Denis de. Sociedade Midiatizada. Rio de Janeiro: Mauad, 2006.

- Ofícios de Cartógrafo: travessias latino-americanas

da comunicação na cultura. São Paulo: Edições Loyola, 2004.

Portal R7. 4,4 bilhões de pessoas não têm acesso à internet. Disponível em: https://tecnoblog.net/166778/4-bilhoes-offline/. Acessado em: 02/06/15.

SHIRKY, Clay. A Cultura da Participação: criatividade e generosidade no mundo conectado. Rio de Janeiro: Zahar, 2011.

ONU BR. No Brasil quase 60\% das pessoas estão conectadas à Internet, afirma novo relatório da ONU. Disponível em: https://nacoesunidas.org/no-brasil-quase-60-das-pessoas-estao-conectadas-a-internet-afirma-novo-relatorio-da-onu/. Acessadoem: 03/06/16.

OROZCO GÓMEZ, Guillermo. LaInvestigación de Las Audiencias “Viejas y Nuevas”. Revista Latinoamericana de Ciencias de la Comunicación, 2010, n.13, Ano 7. São Paulo: ALAIC, 2010.

- La condición comunicacional contemporânea. Desafíos latinoamericanos de la investigación de las interacciones en la sociedad red. In: JACKS, Nilda (org.).Análisis de recepción en América Latina: unrecuento histórico con perspectivas al futuro. Editorial “Quipus”, CIESPAL, Quito-Ecuador, 2011.

WOODWARD, K. Identidade e diferença: uma introdução teórica e conceitual. In: SILVA, Tomaz Tadeu da (Org). Identidade e diferença: a perspectiva dos Estudos Culturais. $1^{\circ}$ ed. Petrópolis, RJ: Vozes, 1999.

Rev.Cad.Comun. Santa Maria, v.20, n.3, art 11, p.211 de 212, set/dez.2016 


\section{RESUMO SOBRE O AUTOR:}

Universidade Federal de Santa Maria (UFSM)

Mestre, Relações Públicas

Santa Maria, Rio Grande do Sul, Brasil

E-mail: laura.roratto@gmail.com

A dissertação que originou este artigo foi orientada pela Prof ${ }^{a}$. Dr ${ }^{\mathrm{a}}$. Liliane Dutra Brignol. e defendida em 15/03/2016, na linha "Mídias e identidades contemporâneas" do POSCOM-UFSM

RECEBIDO EM: 10/07/2016

ACEITO EM: 10/07/2016 